\title{
Suitable reverberation time for halls for rock and pop music
}

\section{Adelman-Larsen, Niels Werner; Thompson, Eric Robert; Gade, Anders Christian}

\section{Published in:}

Acoustical Society of America. Journal

Link to article, DOI:

10.1121/1.3263611

Publication date:

2010

Document Version

Publisher's PDF, also known as Version of record

Link back to DTU Orbit

Citation (APA):

Adelman-Larsen, N. W., Thompson, E. R., \& Gade, A. C. (2010). Suitable reverberation time for halls for rock and pop music. Acoustical Society of America. Journal, 127(1), 247-255. https://doi.org/10.1121/1.3263611

\section{General rights}

Copyright and moral rights for the publications made accessible in the public portal are retained by the authors and/or other copyright owners and it is a condition of accessing publications that users recognise and abide by the legal requirements associated with these rights.

- Users may download and print one copy of any publication from the public portal for the purpose of private study or research.

- You may not further distribute the material or use it for any profit-making activity or commercial gain

- You may freely distribute the URL identifying the publication in the public portal

If you believe that this document breaches copyright please contact us providing details, and we will remove access to the work immediately and investigate your claim 


\title{
Suitable reverberation times for halls for rock and pop music ${ }^{\text {a) }}$
}

\author{
Niels Werner Adelman-Larsen ${ }^{\text {b) }}$ \\ Flex Acoustics, Diplomvej, Bygn. 377, DK-2800 Kgs. Lyngby, Denmark \\ Eric R. Thompson ${ }^{\mathrm{c})}$ \\ Department of Electrical Engineering, Acoustic Technology, Technical University of Denmark, Building 352, \\ DK-2800 Kgs. Lyngby, Denmark \\ Anders C. Gade \\ Gade \& Mortensen Akustik A/S, Hans Edvard Teglers Vej 5, DK-2920 Charlottenlund, Denmark
}

(Received 2 December 2008; revised 9 October 2009; accepted 14 October 2009)

\begin{abstract}
The existing body of literature regarding the acoustic design of concert halls has focused almost exclusively on classical music, although there are many more performances of popular music, including rock and pop. Objective measurements were made of the acoustics of 20 rock music venues in Denmark and a questionnaire was used in a subjective assessment of those venues with professional rock musicians and sound engineers as expert listeners. Correlations between the measurements show that clarity, including bass frequencies down to $63 \mathrm{~Hz}$, is important for the general impression of the acoustics of the hall. The best-rated halls in the study have reverberation times that are approximately frequency independent from 0.6 to $1.2 \mathrm{~s}$ for hall volumes from 1000 to $6000 \mathrm{~m}^{3}$. The worst rated halls in the study had significantly higher reverberation times in the 63 and $125 \mathrm{~Hz}$ bands. Since most audiences at rock concerts are standing, absorption coefficients were measured with a standing audience from $63 \mathrm{~Hz}$ to $4 \mathrm{kHz}$. These measurements showed that a standing audience absorbs about five times as much energy in mid-/high-frequency bands as in low-frequency bands.
\end{abstract}

(C) 2010 Acoustical Society of America. [DOI: 10.1121/1.3263611]

PACS number(s): 43.55.Fw, 43.55.Gx, 43.55.Hy, 43.55.Br [LMW] Pages: 247-255

\section{INTRODUCTION}

There is a long and great tradition of acoustical design for concert halls, evidenced by a large number of books written on the subject, such as from Barron, ${ }^{1}$ Beranek, ${ }^{2}$ and Hoffman $e t a l{ }^{3}$ There have been a number of studies published on the acoustics of concert halls, mainly seeking correlations between objective measurements and subjective perception of the acoustics. ${ }^{4-9}$ This large body of literature focuses entirely on the recommended acoustics for performances of western classical music, including organ music, chamber music, orchestral music, and opera. Even when multipurpose halls are discussed, the purposes intended are usually classical music and spoken-word performances. A large portion of music performances and performance spaces has been ignored in the literature, namely, those of more popular music, such as rock, pop, jazz, country, and others.

A recent survey of performance spaces in Denmark, not including classical music halls or large outdoor arenas, estimated that there had been approximately 12500 live concerts with about 2 million spectators within the popular music genres during $2004 .{ }^{10}$ During the same time frame, the Danish Arts Agency (Kunststyrelsen) estimated (conserva-

\footnotetext{
a) Portions of this study were presented at the 155th Meeting of the Acoustical Society of America (Acoustics '08) and at the 123rd Audio Engineering Society Convention.

${ }^{b)}$ Author to whom correspondence should be addressed. Electronic mail: nwl@flexac.com

${ }^{c)}$ Present address: Hearing Research Center, Boston University.
}

tively large) that there were 2000 classical music concerts in Denmark. This means that there were at least five times more popular music concerts than classical music concerts, and a corresponding ratio of spectators. It is perhaps strange, in light of these numbers, that there has not been more focus on the acoustics of halls for popular music concerts.

Various authors have written loosely about recommendations for acoustics for rock music. For example, in his book $^{1}$ (Chap. 10), Barron mentioned that a highly absorbent acoustic space is preferred for popular music and recommends a reverberation time below $1 \mathrm{~s}$, but there does not appear to be a scientific study behind these recommendations. The present study seeks to fill the void and investigate the optimum acoustic conditions for performances of popular music, particularly for rock music. First, the relevance of the study had to be established by determining whether the acoustics of the performance space play any role in the quality of the experience perceived by the band and the sound engineers. Then, a more comprehensive subjective study was conducted and objective measurements were made on 20 Danish popular music venues using techniques similar to those from Barron. ${ }^{5}$ For the purposes of the present study, it was assumed that the objective acoustic parameters traditionally used to characterize classical music halls can also be applied to rock concert halls. The venues studied were small to medium-sized halls from about $600-7000 \mathrm{~m}^{3}$. There are many rock concerts held in larger spaces (e.g., sports arenas), but those are beyond the scope of the present study. The 
subjective and objective parameters were then correlated in order to determine what is important for good acoustics for popular music performances.

\section{A. The musical genre}

The popular music genre encompasses a broad range of sub-genres, including rock, pop, jazz, punk, and country. These sub-genres have similarities which differentiate them from classical music, but also differences, including instrumentation, frequency balance, and typical sound levels at concerts, which may mean that different acoustic design is desired for the different sub-genres. In order to limit the scope of the current study, the rock and pop sub-genres were chosen as the focus. The two sub-genres are very similar and together make up a large portion of the total popular concerts performed. For the sake of brevity in the paper, the two sub-genres will be grouped together and referred to simply as rock music.

Some of the differences between rock and classical music concerts, which might lead to different requirements for the acoustics of the performance space, will be explained in Secs. I A 1-I A 5.

\section{Instrumentation and sound sources}

Classical music concerts usually are performed by standard orchestral instruments, from the double bass, tuba, and bass drum in the low registers to the violin, piccolo, and triangle, for instance, in the high-frequency range. The instruments are typically not amplified but rather rely on the acoustics of the space to carry the sound to the audience. Rock music, on the other hand, is typically performed on electric and/or acoustic bass and guitars, keyboards, and drum sets. The sound is almost always electrically amplified, so that the sound sources are the on-stage amplifiers and the hall's loudspeaker system (PA), which plays a mix of the instruments controlled by a sound engineer. The PA-system is used to create a desired mix of the instruments with a sufficient sound level, so that the sound carries to all audience members. Not all halls provide PA equipment, requiring bands to bring their own, and some bands only use their own PA equipment, in order to have greater control over the sound. In addition to the PA-system, many sound processors, such as EQ, compression, delay, and artificial reverberation, are used to create the final sound image in a rock concert. The delay and artificial reverberation are often used on vocals, guitars, keyboards, snare drums, tom-toms, and highhats, but it is often recommended to high-pass filter the signals before applying artificial reverberation in order to keep the bass drum and bass guitar from becoming too smeared and indistinct. ${ }^{11}$ The sound that arrives at the listener is a mixture of the sound from the PA and the sound of the reverberant field in the hall. Listeners that are farther from the sound source will experience more of the acoustics of the hall than those within the critical distance ${ }^{12}$ from the sources. Of course, the perceived sound quality in the hall will be affected by the quality of the PA-system and the effects that are applied to the sound, but those factors are beyond the scope of the present study.

\section{Stage acoustic requirements}

A group of musicians performing any kind of music together need to be able to hear each other in order to play as a cohesive unit. ${ }^{13,14}$ This creates challenges in the acoustic design of a classical music stage to provide support through early reflections, particularly for large orchestras. Most rock performers make use of monitors, either on-stage, in-ear or headphones, or a combination of those, which provide a mix of all the instruments and voices to each of the performers. The on-stage monitors are simply loudspeakers set up close to the musician, while the in-ear monitors are generally sound-attenuating earphones. The sound from on-stage monitors is picked up by the microphones, causing unwanted sound in the mix and sometimes feedback. In-ear monitors do not create feedback loops with the microphones, but they attenuate sound from the hall for the musicians. This can mitigate any negative effects of poorly designed acoustics on their performance, but their contact with the audience is reduced, because the audience's audible reaction to the music is also attenuated.

\section{Audience}

During classical concerts, the audience is usually seated in chairs with a density of about 2 people $/ \mathrm{m}^{2}$. ${ }^{1}$ On the other hand, audiences at rock concerts are usually standing and more densely packed, with a density of about 2.7 people $/ \mathrm{m}^{2}$, estimated from a measurement performed to determine the absorption of a standing audience, described below. The difference between standing and seated audiences affects the absorption characteristics and the effective volume of the hall.

\section{Listeners}

For both classical and rock music, the musicians have the best perspective for judging the acoustics on the stage and have been used in prior subjective studies of classical music halls. ${ }^{13,14}$ Rock music concerts also typically have a sound engineer, who actively controls the sound during the concert and can be considered an expert listener with the perspective of the audience. Therefore, for the present study, musicians and sound engineers were asked their subjective impression of the acoustics of the halls.

\section{Balance}

At a typical classical concert, most of the sound energy is in the mid-/high-frequency range, where the mean sound pressure level in the mid-frequencies may be $10 \mathrm{~dB}$ higher than the bass. ${ }^{15}$ At a typical rock concert, the balance is usually quite different with 20-30 dB higher sound levels in the bass than in the mid-frequency range. ${ }^{16}$ With so much more acoustic energy in the bass, it seemed important to consider the acoustics of the halls in the bass range for this study. Many reports of the acoustics of halls or on acoustic treatments only consider frequencies from $125 \mathrm{~Hz}$ and upwards. ${ }^{2,3}$ For purposes of rock music, it may be required to specify halls and materials including the $63 \mathrm{~Hz}$ octave band.

This study was aimed at determining whether acoustics are important for rock concert halls and how the acoustics of 
TABLE I. Details of the twenty surveyed concert halls as of 2005 . Note that several halls have been renovated since this study. $T_{30, B}$ and $T_{30, M / T}$ are the reverberation times in the audience area in the $63-125 \mathrm{~Hz}$ octave bands and in the octave bands from $250 \mathrm{~Hz}$ to $2 \mathrm{kHz}$, respectively. The EDT was measured on the stage in the $63-2000 \mathrm{~Hz}$ octave bands. $D_{50}$ was measured in the audience area and the $63-2000 \mathrm{~Hz}$ octave bands. The BR is the ratio of the average reverberation time in the 63 and $125 \mathrm{~Hz}$ bands to the average reverberation time in the $0.5-2 \mathrm{kHz}$ octave bands. The general ratings are the ordinal positions of the mean general ratings across musicians, across sound engineers, and combined with equal weighting of the two groups.

\begin{tabular}{|c|c|c|c|c|c|c|c|c|c|c|}
\hline \multirow[b]{2}{*}{ Name } & \multirow{2}{*}{$\begin{array}{l}\text { Volume } \\
\left(\mathrm{m}^{3}\right)\end{array}$} & \multirow{2}{*}{$\begin{array}{l}\text { Audience } \\
\text { capacity }\end{array}$} & \multirow{2}{*}{$\begin{array}{c}T_{30, B} \\
(\mathrm{~s})\end{array}$} & \multirow{2}{*}{$\begin{array}{c}T_{30, M / T} \\
\text { (s) }\end{array}$} & \multirow{2}{*}{$\begin{array}{l}\text { EDT } \\
(\mathrm{s})\end{array}$} & \multirow[b]{2}{*}{$D_{50}$} & \multirow[b]{2}{*}{$\mathrm{BR}$} & \multicolumn{3}{|c|}{ General ratings } \\
\hline & & & & & & & & Mus. & SEng. & Comb. \\
\hline Rytmeposten & 655 & 300 & 0.8 & 0.8 & 0.3 & 0.6 & 1.0 & 14 & 10 & 11 \\
\hline Lille Vega & 785 & 500 & 0.5 & 0.7 & 0.4 & 0.7 & 0.7 & 1 & 6 & 3 \\
\hline Loppen & 890 & 350 & 0.9 & 0.8 & 0.5 & 0.7 & 1.2 & 5 & 13 & 9 \\
\hline Skråen & 1100 & 375 & 1.5 & 0.8 & 0.9 & 0.4 & 1.8 & 13 & 12 & 13 \\
\hline Paletten & 1420 & 375 & 1.0 & 0.9 & 0.7 & 0.7 & 1.0 & 8 & 8 & 8 \\
\hline Stars & 1440 & 400 & 0.6 & 0.6 & 0.3 & 0.8 & 0.9 & 1 & 1 & 4 \\
\hline Voxhall & 1600 & 500 & 0.9 & 0.6 & 0.5 & 0.7 & 1.3 & 7 & 5 & 6 \\
\hline Sønderborghus & 1600 & 420 & 1.2 & 1.0 & 0.8 & 0.6 & 1.3 & 20 & 18 & 19 \\
\hline Musikhuzet & 2080 & 700 & 1.1 & 0.9 & 1.1 & 0.5 & 1.2 & 9 & 17 & 12 \\
\hline Godset & 2150 & 700 & 0.7 & 0.8 & 0.5 & 0.6 & 0.8 & 6 & 4 & 5 \\
\hline Magasinet & 2540 & 525 & 1.9 & 1.3 & 1.3 & 0.3 & 1.4 & 12 & 19 & 18 \\
\hline Pumpehuset & 3000 & 600 & 1.2 & 1.1 & 1.0 & 0.6 & 0.9 & 16 & 15 & 15 \\
\hline Forbrændingen & 3050 & 450 & 1.1 & 0.9 & 0.5 & 0.8 & 1.2 & 19 & 11 & 14 \\
\hline Train & 3300 & 900 & 0.8 & 1.0 & 0.4 & 0.7 & 0.9 & 3 & 2 & 2 \\
\hline Slagelse & 3800 & 700 & 1.8 & 1.6 & 1.0 & 0.5 & 1.1 & 17 & 20 & 20 \\
\hline Viften & 3950 & 700 & 2.6 & 1.2 & 1.1 & 0.6 & 2.0 & 18 & 14 & 16 \\
\hline Amager Bio & 4500 & 1000 & 1.2 & 1.0 & 0.8 & 0.6 & 1.1 & 4 & 9 & 7 \\
\hline Torvehallerne & 5400 & 700 & 1.2 & 1.5 & 0.9 & 0.5 & 0.8 & 15 & 16 & 17 \\
\hline Store Vega & 5800 & 1430 & 1.4 & 1.2 & 0.7 & 0.7 & 1.1 & 2 & 3 & 1 \\
\hline Tobakken & 6500 & 1200 & 1.5 & 1.0 & 0.8 & 0.6 & 1.4 & 11 & 7 & 10 \\
\hline
\end{tabular}

a hall should be designed for the best experience for the audience and the musicians. The literature on the acoustics of classical music halls has many key objective metrics and determined their correlation with perceived sound quality. ${ }^{2}$ For this first study of the acoustics of rock/pop music halls, the main focus was to determine recommendations for the reverberation time $T_{30}$ as a function of frequency and hall volume for small- and medium-sized halls.

\section{METHODS}

A survey was conducted on the perceived acoustics of 20 rock concert halls around Denmark and objective measurements were carried out in each hall. A list of the halls and some acoustic measurements from them are shown in Table I. The halls were either dedicated or multi-purpose halls, where many of the dedicated halls were converted to cinemas or industrial halls, and many of the multi-purpose halls were cultural centers, common around Scandinavia, that may also host theater productions, for example.

\section{A. Subjective survey}

There have been three primary methods for conducting subjective studies of the acoustics of concert halls for classical music, each with its advantages and disadvantages. One method has been to create a virtual concert hall in a laboratory, where either recordings from halls or simulations from a room acoustics program (e.g., ODEON and EASE) are presented to the listeners. The acoustics could either be simulated with an array of loudspeakers in an anechoic chamber ${ }^{17,18}$ or auralized and presented over headphones. ${ }^{9}$
With this method, listeners can quickly rate many halls without having to travel great distances. Some other benefits are that halls can be presented anonymously and blindly so that there is no bias based on a hall's reputation or visual appeal, and the exact same performance of a piece can be evaluated in all halls and positions. Despite these advantages, it can be difficult to get truly qualified listeners, e.g., professional musicians with their busy schedules, to participate in a laboratory experiment.

As an alternative, listening tests can be performed in an existing hall that has the possibility of changing the acoustics. ${ }^{5,13}$ However, the changes that can be made to the acoustics in such a hall are often quite limited and the results may not be generalizable to all halls.

Surveys have also been done on existing halls through interviews of people who have experience with the acoustics in many halls. ${ }^{19}$ Unfortunately, acoustic memory can be very short and is likely to be colored by many non-acoustic factors, which can make the comparison of halls with this method less precise than if the sound impression from the halls can be presented quickly in sequence in the laboratory. In spite of this challenge, this method was selected for the subjective evaluation of the halls in the present study, primarily because it was deemed to be important that the evaluation of the halls was made by people who had great experience working in and listening to the halls, namely, professional musicians and sound engineers. It was assumed that the listeners chosen for the subjective study had worked often enough in many or all of the halls to be able to remember and appropriately judge their acoustics.

Surveys for all 20 halls were sent to 50 touring musi- 


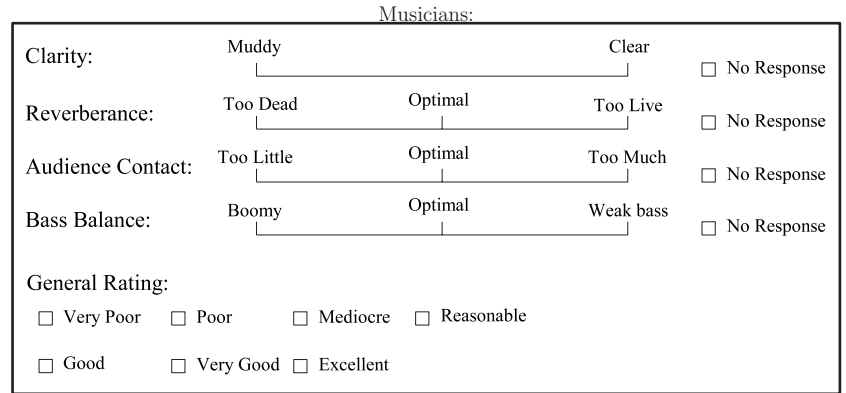

Sound Engineers:

\begin{tabular}{|c|c|c|c|c|c|c|}
\hline \multirow{2}{*}{\multicolumn{2}{|c|}{ Clarity Bass: }} & \multirow{2}{*}{\multicolumn{2}{|c|}{ Muddy }} & \multicolumn{3}{|c|}{ Clear } \\
\hline & & & & & & $\square$ No Response \\
\hline \multicolumn{2}{|c|}{ Clarity Mid/Treble: } & Muddy & & & Clear & $\square$ No Response \\
\hline \multicolumn{2}{|l|}{ Reverberance: } & \multicolumn{2}{|l|}{ Too Dead } & $\begin{array}{c}\text { Optimal } \\
\perp\end{array}$ & Too Live & $\square$ No Response \\
\hline Bass Balance: & & \multicolumn{2}{|c|}{ Boomy } & $\begin{array}{c}\text { Optimal } \\
\perp\end{array}$ & Weak bass & $\square$ No Response \\
\hline \multicolumn{7}{|c|}{ General Rating: } \\
\hline$\square$ Very Poor & $\square$ Poor & or & Mediocre & $\square$ Reasonable & & \\
\hline$\square$ Good & $\square$ Very & ry Good & $\checkmark$ Excellent & & & \\
\hline
\end{tabular}

FIG. 1. Musicians' and sound engineers' questionnaire forms for the subjective rating of each of the concert halls (translated from Danish).

cians and 18 sound engineers in Denmark, of which $25 \mathrm{mu}-$ sicians and 8 sound engineers responded. The musicians and sound engineers were selected from the bands that had performed most often in Denmark and at a minimum of 8 of the 20 halls within the 3 year period before the survey was performed. There were eight bands that fulfilled the criteria, as well as several freelance musicians and sound engineers.

The first page introduced the survey by saying (translated from Danish): "As a musician, one evaluates venuesconsciously or unconsciously - based on factors, such as: how good is the visual contact with the audience, is the temperature appropriate, is the service good, etc. In this anonymous survey, the focus is on the acoustics of the venue for the performers. This means: how does the hall respond to the music that is played-judged independently (as far as possible) of the PA-system, the monitor technicians, etc." Then the survey asked what kind of monitors the band uses (in-ear, headphone, stage, other), whether the respondent discusses the acoustics of halls with their colleagues (yes/no), how important acoustics are for the respondent (very, somewhat, a little, not important-translated from Danish), whether the respondent had chosen not to play in certain halls because of the acoustics (yes/no), and whether the respondent thought that possible negative effects of acoustics could be mitigated through the use of in-ear monitors (very, somewhat, a little, no). Then, the respondents were asked to complete a questionnaire for each hall, asking for ratings of the halls on several acoustic aspects.

The design of the questionnaire for each hall was based on the questionnaire used by Barron. ${ }^{5}$ The musicians' form is shown in Fig. 1, translated from Danish to English. The first two scales, "Clarity" and "Reverberance," are the same as on Barron's questionnaire. For the present study, Barron's ratings of "Envelopment," "Intimacy," and "Loudness" were dropped because these are expected to be more influenced by the PA-system configuration in a rock concert than by the room acoustics. Instead, the scales "Audience Contact" and "Bass Balance" were added. The sound engineers' form differed from the musicians' form on two questions. The Clarity rating was divided into "Clarity Mid-Treble" and "Clarity Bass," and the Audience Contact rating was removed. Each group of respondents had four attributes to rate with a continuous scale and a general rating with discrete values for each hall. The instructions were that the respondents should complete as many forms as possible, but should at least provide a general rating for all of the halls with which they were familiar.

It was expected that the three subjective ratings Clarity, Reverberance, and Bass Balance would be correlated with the objective measurements $D_{50}$ ("Deutlichkeit" or "Definition"), $T_{30}$ or EDT (reverberation time or early decay time), and BR (bass ratio). The Audience Contact rating came from the first author's own experience as a professional rock and jazz musician that the acoustics of the stage and hall can have a strong effect on the feeling of contact with an audience.

The respondents were free to set a mark anywhere on the continuous lines. The lines were $10.8 \mathrm{~cm}$ long in the original format with an "optimal" mark at the center point for all but the Clarity ratings. There are advantages and disadvantages to including the optimal mark on the scales. By including the optimal mark, the respondents were given a reference point for where they thought the best halls should lie on the scale. However, an optimal mark can make the scales non-linear, because the optimal point of the scale may not be exactly half-way between the end-points and may be at a different position for each respondent. The positions of the respondents' marks on the line were measured, assuming a linear scale, and the data were assembled for statistical and correlational analysis of the data.

\section{B. Objective measurements}

The objective measurements were performed in accordance with ISO 3382:1997. ${ }^{20}$ Measurements were made on the stage and in the audience area, using an omni-directional, dodecahedral speaker array with a subwoofer as the sound source, and a second set of measurements was made using the halls' PA-systems. The DIRAC software package (Acoustics Engineering, v3.0) was used on a laptop computer to generate a frequency sweep signal and to calculate the room impulse response. An AKG C34 condenser microphone in omni-directional mode was used to measure the impulse response. At least three measurements were conducted on the stage and another three (minimum) measurements in the audience area, including one point at the sound engineer's position. In each hall with a balcony, measurement positions were added on and below the balcony. The same microphone positions were used with both the dodecahedral array and the PA-system. According to ISO 3382, at least two source positions should be used, which was possible when measuring with the dodecahedral array, with the source placed at two different positions on the stage. However, when the PAsystem was used as the source, it could not be moved to a different position, so only one source position was used for 
these measurements. The PA-systems' room equalizers were bypassed for the measurements.

The objective measurements were conducted in unoccupied halls and included reverberation time $\left(T_{30}\right)$, EDT, and Deutlichkeit/definition $\left(D_{50}\right)$. In a previous study, ${ }^{21}$ a correlation coefficient of 0.96 was found between $D_{50}$ and Clarity $\left(C_{80}\right)$ in similar halls. Also, since the rhythmic information and lyrics are so important for this genre, it was assumed that the intelligibility/clarity parameter with the shortest integration time was the most relevant. Therefore, $D_{50}$ was chosen over $C_{80}$. The correlation of these metrics with the general ratings of the halls give a starting point for the design of acoustics for rock concert halls.

Sound absorption coefficients can be found for a seated audience $^{22}$ and absorption areas for single standing persons. ${ }^{23}$ Simply multiplying the absorption area of a single standing person by the number of people in attendance will overestimate the sound absorption, because a large portion of the absorption area will be rendered ineffective by the presence of other tightly packed members of the audience. Therefore, the sound absorption coefficient of a standing rock audience was measured by comparing the reverberation times of a concert hall with and without audience present. The measurement was made using the DIRAC software in the Pumpehuset concert hall in Copenhagen during a break (with audience present) and after the concert (empty hall). The concert hall is a rectangular hall $\left(32.3 \times 11.6 \times 8 \mathrm{~m}^{3}\right)$ with an audience area of $225 \mathrm{~m}^{2}$ and capacity of 600 people, or an approximate density of 2.7 people $/ \mathrm{m}^{2}$. The floor in the hall was concrete with a rubber coating.

\section{RESULTS AND DISCUSSION}

\section{A. First page of the questionnaire}

The 25 musicians who responded to the questionnaire came from 11 different groups. There were eight drummers, seven bass players, five guitar players, three keyboardists, and two singers. In response to the question "How important are the acoustics of a venue for you?" seven out of eight sound engineers and 17 out of 25 musicians said that acoustics are "very important" to them. The remaining sound engineer and seven musicians said that acoustics are "important" and the remaining musician said that acoustics are only "slightly important." Two of the eight sound engineers surveyed and 8 of the 25 musicians said that they have chosen not to play in certain halls because of the acoustics. All sound engineers and all musicians said that they discuss the acoustics of specific halls with colleagues. Five sound engineers reported that their bands used in-ear monitors, seven reported using on-stage monitors, and one reported using headphones as monitors (note that the respondents could choose more than one monitor type). Fourteen musicians reported using in-ear monitors, 19 use on-stage monitors, and 3 musicians (all drummers) reported using headphones. On the question of whether in-ear monitors can help to mitigate the possible bad effects of a hall's acoustics, four sound engineers and nine musicians responded "very much," three sound engineers and eight musicians responded "somewhat," and one sound engineer and three musicians responded "a little." The remaining five musicians either did not respond or responded "don't know."

These results on the importance of acoustics and whether the respondents discuss acoustics with their colleagues are probably biased, in that those who find acoustics important and discuss acoustics are more likely to respond to a survey on acoustics. The responses to the question on whether the respondent ever chose not to play in certain halls because of the acoustics may also be skewed. Some of the musicians surveyed may not be involved in booking concerts and may not be aware that their band has declined jobs because of the acoustics of the hall. For example, two musicians from the same band were surveyed. One responded "yes" that they choose not to play certain halls, and the other responded "no" that they do not. Presumably, the one who responded yes is involved in booking concerts, while the one who responded no just shows up to play where he or she is told. Overall, these results showed that acoustics are important for rock musicians and sound engineers, and this provided further encouragement to pursue the investigation.

\section{B. General ratings of the halls}

The general ratings were analyzed by assigning a number from 1 to 7 to the general ratings options, where a 1 corresponded to "Excellent" and 7 corresponded to "Very Poor." The mean general rating was then calculated for the musicians and for the sound engineers, and the combined rating was calculated as the mean of the two groups. The ordinal rank of the halls' ratings from 1 (best) to 20 (worst) for each group and the combined rating are shown in Table I. The halls are sorted in order from smallest to largest by volume, and it is interesting to note that there is no correlation between the size of the hall and the overall rating.

Interestingly, the driest hall, Stars, is in tenth place in the musicians' ratings but is the favorite of the sound engineers, which moves it to the fourth best rating overall. Stars was also rated driest on the "Reverberance" scale (the only hall rated by the musicians as "too dry"), significantly drier ( $p$ $<0.05)$ than all but one other hall. So even though the sound engineers appreciate the recording studio quality of the hall, it is a good example that a hall can be too dry for musicians. The four lowest rated halls have relatively high $T_{30}$ and typically longer reverberation in the low frequencies. Viften has a very long reverberation time at $63 \mathrm{~Hz}$ (over $3 \mathrm{~s}$ ) and much shorter reverberation (around $1 \mathrm{~s}$ ) for frequencies above $500 \mathrm{~Hz}$. This is also the hall that the sound engineers rated the lowest on Clarity Bass.

\section{Correlations between subjective ratings}

There were significant differences between halls seen in the analysis [analysis of variance (ANOVA)] of the responses on every rating scale except for Audience Contact. The ratings of Audience Contact were about the same for all halls for each respondent, indicating that the respondents may not have really understood the category. However, even within the small variance, there were significant differences between respondents, so the ratings of Audience Contact 
TABLE II. Correlation coefficients for the musicians' subjective ratings (Clarity, Reverb, Audience Contact, and Bass Balance). Significant correlations $(|r|>0.5)$ are shown in bold.

\begin{tabular}{lcccc}
\hline \hline & Clarity & Reverb & Aud. Cont. & Bass Bal. \\
\hline Reverb & $\mathbf{- 0 . 5 8}$ & & & \\
Aud Cont. & 0.02 & 0.00 & & \\
Bass Bal. & $\mathbf{0 . 6 7}$ & -0.49 & 0.06 & \\
Gen. Rat. & $\mathbf{0 . 7 5}$ & -0.42 & 0.21 & $\mathbf{0 . 7 0}$ \\
\hline \hline
\end{tabular}

may be based more on non-acoustic factors, such as the role of the respondent in the band or position on the stage (i.e., lead singers may feel more contact with the audience than drummers).

Correlation coefficients were calculated pairwise between the five subjective ratings of the musicians and the sound engineers (see Tables II and III, respectively). The musicians' "General Rating" was strongly correlated with Clarity and Bass Balance, indicating a preference for crisp, not boomy halls. Clarity and Reverberation also have a strong inverse correlation, as opposed to some other studies $^{4,5}$ that found no correlation between the two parameters.

There were also strong correlations between the sound engineers' subjective ratings (Table III) of General Rating and the two Clarity' ratings (bass and mid/treble), indicating a preference for crisp sound. The Clarity ratings from the two frequency ranges may reflect quite different acoustic profiles in the different frequency ranges, as seen in the data in Table I. A look at the Clarity data set showed that if there was a difference in the ratings, then "Clarity Mid/Treble" was generally rated as more clear than Clarity Bass.

\section{Objective measurements}

\section{Standing audience absorption}

Figure 2 shows absorption coefficients for a standing audience, measured as described in Sec. II B, along with coefficients for a seated audience from Meyer et al. ${ }^{19,22}$ The data show that the absorption coefficients of a standing audience is five to six times higher in the mid-high-frequency bands than in the low-frequency bands, and that there is very little absorption in the low frequencies. Note that the absorption coefficients that are greater than 1 can be attributed to an audience not being a simple two-dimensional surface. Therefore, the effective absorption area of an audience is larger than the area they cover on the floor. In addition, there will be complex diffraction effects between and around audience members, and a reduction in the effective acoustic volume of

TABLE III. Correlation coefficients for the sound engineers' subjective ratings (Clarity Bass, Clarity Mid/Treble, Reverb, and Bass Balance). Significant correlations $(|r|>0.5)$ are shown in bold.

\begin{tabular}{lcccc}
\hline \hline & Clarity B & Clarity $M / T$ & Reverb & Bass Bal. \\
\hline Clarity $M / T$ & $\mathbf{0 . 6 6}$ & & & \\
Reverb & $\mathbf{- 0 . 5 0}$ & -0.46 & & \\
Bass Bal. & $\mathbf{0 . 5 1}$ & 0.25 & -0.38 & \\
Gen. Rat. & $\mathbf{0 . 7 4}$ & $\mathbf{0 . 7 2}$ & $\mathbf{- 0 . 6 4}$ & $\mathbf{0 . 5 0}$ \\
\hline \hline
\end{tabular}

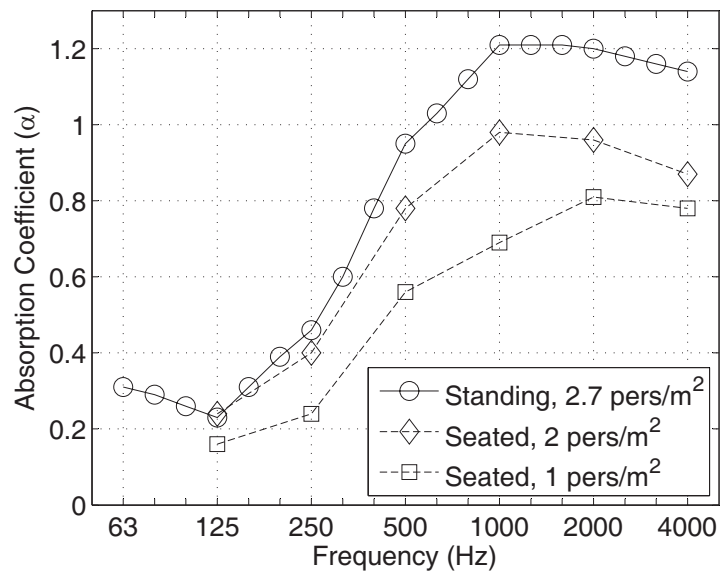

FIG. 2. Absorption coefficients for an audience. Standing audience with a density of about 2.7 people $/ \mathrm{m}^{2}$ (circles) and a seated audience on wooden chairs with a density of 2 people $/ \mathrm{m}^{2}$ (diamonds) (Refs. 19 and 22) and 1 person $/ \mathrm{m}^{2}$ (squares) (Refs. 19 and 22).

the hall. Note that the edge diffraction effects mean that the exact absorption coefficients may depend on the perimeter of the audience area. The imbalance in absorption coefficients across frequencies means that the presence of an audience in a hall will lead to lower mid-high-frequency reverberation times, as compared to the empty hall, but will have little effect in the bass-frequencies. In addition, PA-systems are generally designed to be highly directive in the high frequencies, radiating most of their energy directly at the audience, but can be assumed to be nearly omni-directional in the lowfrequency ranges. ${ }^{24}$ Therefore, a hall that has approximately equal reverberation times across frequencies when empty will have disproportionately long low-frequency reverberation times when the hall is full. In order to have a balanced hall with a full audience, the reverberation times in the lowfrequency bands would have to be lower than in the midfrequency bands when measured in an empty hall.

\section{PA vs omni-directional source measurements}

Objective measurements were made in the halls using both the omni-directional (dodecahedral) speaker and the halls' PA-systems as the sound source. This allowed a comparison between the results obtained with the different sources. Three-way ANOVAs were conducted on the $T_{30}$, EDT, and $D_{50}$ data with main factors of source (omni, PA), receiver area (audience, stage), and frequency with a threshold of significance at $p=0.05$. The $T_{30}$ analysis showed no significant main effects of source or receiver area, and no source-receiver interaction. There was a significant main effect of source on the EDT measurements, a significant main effect of location, and a significant source-location interaction with $p<0.01$ for all three analyses. Post hoc analysis showed that the omni-stage EDT measurement was significantly lower than the omni-audience and the PA measurements. The PA-stage EDT was significantly lower than the PA-audience EDT, but there was no significant difference between the two audience measurements. The main effects of source, location, and frequency were all significant at the $p$ $<0.001$ level for the $D_{50}$ measurements, as was the sourcelocation interaction. The source-location/frequency interac- 


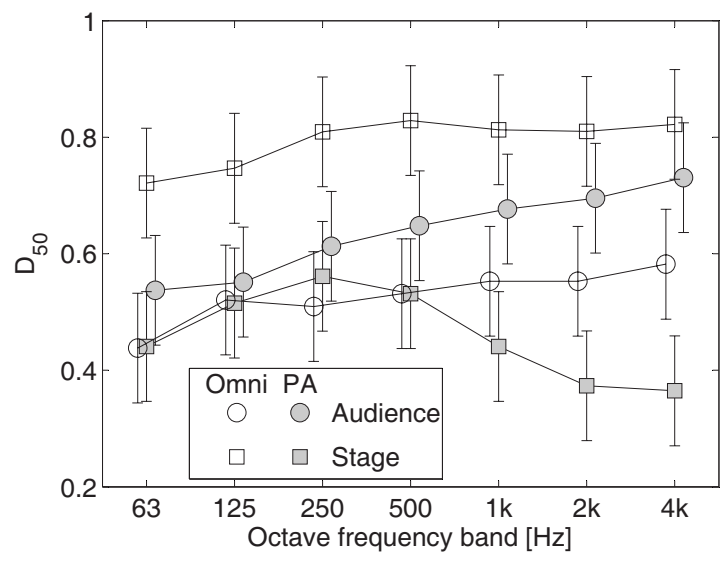

FIG. 3. Mean $D_{50}$ values across halls measured with an omni-directional source (open symbols) and with the hall's PA-system (gray filled symbols), in the audience area (circles) and on-stage (squares). The error bars show the $95 \%$ confidence intervals for the differences.

tion (see Fig. 3) was also significant with $p<0.01$.

There were no significant differences between the omniand PA measurements in the audience. Of course, there will be positions in a hall, for which there will be a difference in the $D_{50}$ measurements, but for a spatial average over many positions in the hall, no significant differences were found. The $D_{50}$ measured on-stage with the omni-source are higher than the other measurements, because the measurement positions were relatively close to the source, so the direct-toreverberant energy ratio was high. The $D_{50}$ measured onstage with the PA are much lower than those measured with the omni-source. In addition, the PA-stage measurement shows much lower $D_{50}$ with the higher frequency bands. This is because the PA-systems are generally in front of the stage and are pointed toward the audience. This means that the PA speakers do not radiate much high-frequency energy onto the stage, due to their directivity, so most of the high-frequency energy on-stage is from the reverberant sound field, resulting in a low $D_{50}$.
These data show that the PA-system can be used for acoustic measurements in the audience area of a hall but should not be used for measurements on the stage. It should be noted that measurements made with the PA-system as a source will not be compliant with ISO $3382 .^{20}$

\section{E. Correlation between subjective and objective parameters}

Correlation coefficients were calculated between the mean subjective parameters and the objective parameters $T_{30, W}(63-2000 \mathrm{~Hz}), \quad T_{30, B}(63-125 \mathrm{~Hz}), \quad T_{30, M T}(250-2000$ $\mathrm{Hz}), \operatorname{EDT}(63-2000 \mathrm{~Hz}), D_{50}(63-2000 \mathrm{~Hz})$, and BR (the ratio of $T_{30}(63-250 \mathrm{~Hz})$ to $\left.T_{30}(500-2000 \mathrm{~Hz})\right)$ measured with the omni-source for each hall and are shown in Table IV, with significant correlations $(p<0.05)$ marked in bold. The musicians' subjective parameter Audience Contact was not correlated with any of the objective parameters, reinforcing the idea that this parameter may be based more on nonacoustic effects. All of the other subjective parameters for the musicians and the sound engineers were correlated with $T_{30, W}$ and with EDT. The musicians' General Rating was significantly correlated with $T_{30, W}$, but the correlations with $T_{30, B}$ and $T_{30, M T}$ were not significant. The sound engineers' "Clarity B" and "Clarity $\mathrm{M} / \mathrm{T}$ " ratings were correlated with $D_{50}$ from the audience area, as had been expected, and the musicians' Clarity rating was correlated with $D_{50}$ on the stage. Also, the sound engineers Clarity $\mathrm{M} / \mathrm{T}$ rating was significantly correlated with $T_{30, M T}$, but not with $T_{30, B}$. The musicians' Bass balance rating was correlated with the measured BR, but the sound engineers' was not.

\section{F. Correlation between $T_{30}$, hall volume, and the general rating}

The reverberation time of a hall generally increases with hall volume, and listeners' expectations of hall quality also require longer reverberation times from larger halls. For ex-

TABLE IV. Correlation coefficients between the musicians' and sound engineers' mean subjective ratings and the measured objective parameters. $T_{30}$ is the mean reverberation time measured in the audience area with the omni-directional source, with subscripts $W$ for wideband from $63-2000 \mathrm{~Hz}, B$ for bass from $63-125 \mathrm{~Hz}$, and $M T$ for $\mathrm{mid} /$ treble from $250-2000 \mathrm{~Hz}$. EDT is the mean early decay time from $63-2000 \mathrm{~Hz}$ measured on the stage with the omni-directional source. The $D_{50}$ values are the mean from $63-2000 \mathrm{~Hz}$ measured in the audience area with the PA source (subscript $A$ ) and with the omni-source on the stage (subscript $S$ ). BR is the bass ratio, i.e., ratio of $T_{30}(63-250 \mathrm{~Hz})$ and $T_{30}(500-2000 \mathrm{~Hz})$. Significant correlations $(p<0.05)$ are marked in bold.

\begin{tabular}{|c|c|c|c|c|c|c|c|c|}
\hline & & \multicolumn{7}{|c|}{ Objective measurements } \\
\hline \multicolumn{2}{|c|}{ Subjective ratings } & $T_{30, W}$ & $T_{30, B}$ & $T_{30, M T}$ & EDT & $D_{50, A}$ & $D_{50, S}$ & $\mathrm{BR}$ \\
\hline \multirow[t]{5}{*}{ Musicians } & General rating & 0.52 & 0.50 & 0.46 & 0.51 & -0.33 & -0.50 & 0.37 \\
\hline & Clarity & -0.63 & -0.55 & -0.61 & -0.71 & 0.47 & 0.66 & -0.31 \\
\hline & Reverberance & 0.69 & 0.60 & 0.66 & 0.77 & -0.35 & -0.56 & 0.26 \\
\hline & Bass balance & -0.65 & -0.69 & -0.52 & -0.71 & 0.41 & 0.52 & -0.53 \\
\hline & Audience contact & -0.20 & -0.15 & -0.21 & -0.13 & 0.32 & 0.31 & -0.01 \\
\hline \multirow[t]{5}{*}{ Sound Eng. } & General rating & 0.69 & 0.58 & 0.68 & 0.77 & -0.65 & -0.51 & 0.32 \\
\hline & Clarity B & -0.80 & -0.73 & -0.74 & -0.81 & 0.55 & 0.58 & -0.42 \\
\hline & Clarity $M / T$ & -0.60 & -0.49 & -0.60 & -0.75 & 0.70 & 0.36 & -0.25 \\
\hline & Reverberance & 0.74 & 0.60 & 0.76 & 0.80 & -0.58 & -0.61 & 0.26 \\
\hline & Bass balance & -0.70 & -0.65 & -0.64 & -0.57 & 0.20 & 0.58 & -0.33 \\
\hline
\end{tabular}




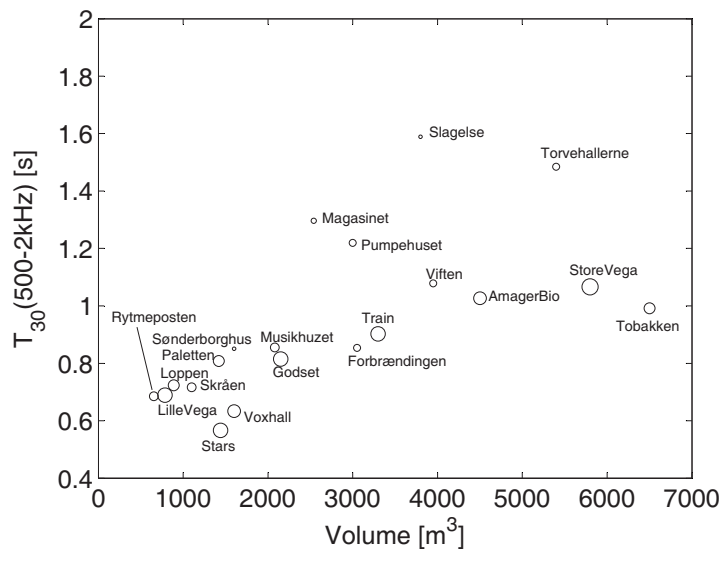

FIG. 4. Mean measured $T_{30}$ on the stage and in the audience area from $500 \mathrm{~Hz}$ to $2 \mathrm{kHz}$ vs hall volume for the 20 halls in the study (empty halls). The size of the marker indicates the combined general rating of the hall with better ratings having larger markers.

ample, Train and Sønderborghus have very similar reverberation times across frequency; however, Train was rated much higher than Sønderborghus. Adding the dimension of Volume can help clarify the ratings. Figure 4 shows a plot of the mean reverberation time of the stage and audience areas measured with the omni-directional source in the $500 \mathrm{~Hz}$ to $2 \mathrm{kHz}$ octave bands for each hall as a function of its volume. The halls with a higher combined rating (see Table I) are marked with a larger circle in Fig. 4 than the lower rated halls. From this, it can be seen that Train has about twice the volume of Sønderborghus, so should be expected to have a longer reverberation time. Most of the halls in the plot fall in an area that increases in $T_{30}$ with volume. Those that are significantly beyond this area are rated the lowest (Slagelse, Magasinet); however, there is an overlap of highly rated and mediocre, or even poorly rated, halls. For example, Viften and Sønderborghus are close to the main cluster, even though they are two of the five lowest rated halls overall. This means that $T_{30}$ in the $500-2000 \mathrm{~Hz}$ bands is a poor predictor of the general hall rating.

Greater separation between the highly rated and mediocre halls can be achieved by including the bass-frequencies in the model. Figure 5 shows the same data as Fig. 4, except that all frequency bands from $63 \mathrm{~Hz}$ to $2 \mathrm{kHz}$ are included. Viften now lies well away from the main cluster because it has a disproportionately long reverberation time in the bassfrequencies. This indicates the importance of including the bass-frequencies in the mean hall reverberation time as a means of predicting the general impression of the acoustics. A weighted regression line was fitted to the data shown in Fig. 5 for the ten top-rated halls, with double weight for the five top-rated halls. The equation for this line is

$$
T_{30}=0.55 \mathrm{~s}+1.04 \times 10^{-4} \mathrm{~V} \mathrm{~s} / \mathrm{m}^{3},
$$

where $V$ is the volume of the hall. (Note that recommended reverberation times in the literature are usually proportional to the logarithm of hall volume. Further studies extending this investigation to larger hall volumes may reveal a similar trend for rock music halls.) This model explained $80 \%$ of the variance $\left(R^{2}\right)$ of the best halls' data.

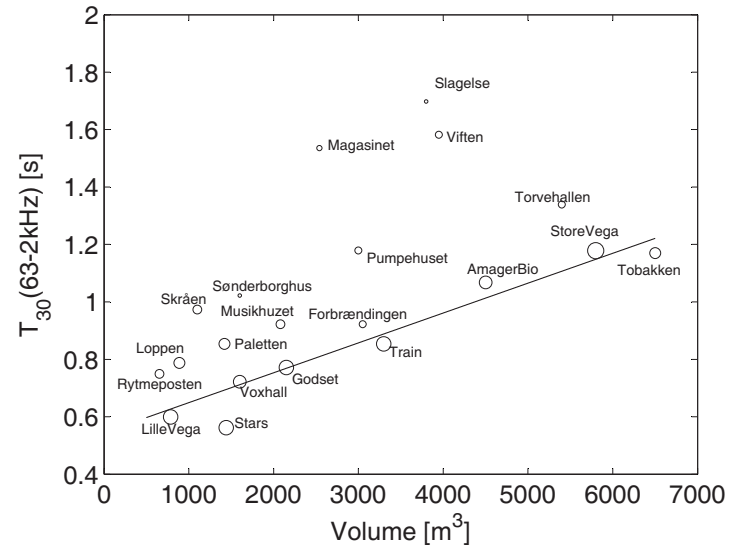

FIG. 5. Mean measured $T_{30}$ on the stage and in the audience area from $63 \mathrm{~Hz}$ to $2 \mathrm{kHz}$ vs hall volume for the 20 halls in the study (empty halls). A larger marker indicates a better combined general rating. The line shows the recommended reverberation time as a function of hall volume.

By separating the halls into groups of the best- and worst-rated halls, some trends can be seen that can be used to help design the acoustics of a rock concert hall. Figure 6 shows the estimates of the mean and standard errors of the reverberation time as a function of hall volume by frequency band. The model shown in Eq. (1) was used to normalize the $T_{30}$ data for an analysis of the differences between the two groups. A two-way ANOVA on the normalized $T_{30}$ with main effects of group (best/worst) and frequency band showed a significant effect of group $[F(1,112)=33.7, p \ll 0.001]$ and of frequency $[F(6,112)=4.5, p<0.001]$, as well as a significant interaction $[F(6,112)=2.32, p<0.05]$. Similar differences were also found using only the musicians' ratings and the stage acoustics, as well as for the engineers' ratings with the audience acoustics. Therefore, the results are presented for the combined ratings with the overall hall mean reverberation times. The estimated mean normalized reverberation times for the two groups and $95 \%$ confidence intervals are shown as a function of frequency band in Fig. 6. This shows that the normalized reverberation times are significantly lower in the low-frequency bands for the best-rated halls, and that there is little difference in the high-frequency bands. The

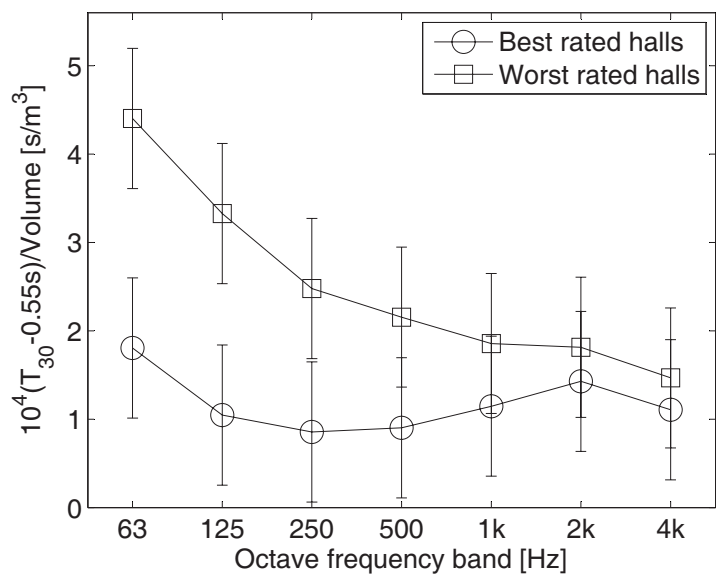

FIG. 6. Linear transform of $T_{30}$ by volume as a function of frequency band, grouped by best- and worst-rated halls. Shown are the estimates of the means of $\left(T_{30}-0.55 \mathrm{~s}\right) /$ volume and $95 \%$ confidence intervals for the two groups. 
worst-rated halls in this study tend to have sloping reverberation-time profiles with higher $T_{30}$ in the bass than in the higher frequency bands, while the best halls have, on average, approximately equal reverberation times across frequency. These data suggest that the best halls should have flat reverberation time profiles across frequencies and that the reverberation times should be close to the line drawn in Fig. 5, i.e., 0.6-1.2 s for halls from $1000-7000 \mathrm{~m}^{3}$, respectively. Of course, there are many other acoustic and nonacoustic factors that can influence the general acoustic impression of a concert hall, but those are beyond the scope of the present study.

\section{CONCLUSIONS}

In the subjective survey, both musicians and sound engineers find the acoustics of the concert hall very important for their performance. More than one in three musicians responding reported choosing not to play in a hall on account of bad acoustics. Therefore, it is important to properly design the acoustics for a rock or multipurpose venues.

A standing audience at a rock concert will absorb five to six times as much energy in the mid-high-frequency bands than in the low-frequency bands. If an empty hall has a disproportionately long reverberation time in the bass, then the addition of an audience will only make the bass ratio even more unbalanced. A modern rock or pop performance has very high sound levels in the bass-frequencies, so it is important to consider the bass acoustics in the hall.

The general acoustic impression of a rock concert hall is strongly correlated with the perceived clarity of the hall, also in the bass-frequencies. Therefore, it is critical to consider the bass acoustics, including the $63 \mathrm{~Hz}$ octave band, in the acoustic design of the hall. This means that manufacturers of acoustic treatments should also measure and report the acoustic properties down to $63 \mathrm{~Hz}$.

Objective acoustic measurements were made with both an omni-directional source and with the halls' PA-system. There were no significant differences in the measured acoustic parameters between the sources when measured in the audience area, but there were large differences seen on the stage. Therefore, the PA-system may be usable as a sound source for measurements in the audience area but should definitely not be used to characterize the stage area.

The best-rated halls in the study have a flat reverberation time profile across frequencies and have a reverberation time as a function of volume close to Eq. (1), while the worstrated halls had significantly higher reverberation times in the bass-frequencies. Therefore, it is recommended that rock venues should be designed with reverberation times close to Eq. (1). This recommendation is valid for small to mediumsized halls and needs to be verified for scalability to larger halls. In order to help predict the quality of a hall, when publishing data or writing a report on a hall used for rock music, the reverberation times for the hall should be reported in frequency bands from $63 \mathrm{~Hz}$ and up. Of course, $T_{30}$ is only one aspect of acoustic design. Further studies should investigate the placement of reflective and absorptive sur- faces in the hall and stage area to optimize other acoustic parameters to meet the desires of the musicians, sound engineers, and audience.

Note that several of the halls listed here have been renovated since the measurements for this study were performed in 2005, so the acoustic data listed here and the subjective impressions may not be up-to-date with the current state of the halls.

${ }^{1}$ M. Barron, Auditorium Acoustics and Architectural Design (E \& FN Spon, London, 1993)

${ }^{2}$ L. Beranek, Concert Halls and Opera Houses: Music, Acoustics, and Architecture, 2nd ed. (Springer, New York, 2003).

${ }^{3}$ Halls for Music Performance: Another Two Decades of Experience 19822002, edited by I. Hoffman, C. Storch, and T. J. Foulkes (Acoustical Society of America, Melville, NY, 2003).

${ }^{4}$ R. J. Hawkes and H. Douglas, "Subjective acoustic experience in concert auditoria," Acustica 24, 235-250 (1971).

${ }^{5}$ M. Barron, "Subjective study of British symphony concert halls," Acustica 66, 1-14 (1988).

${ }^{6}$ T. J. Cox and B. M. Shield, "Audience questionnaire survey of the acoustics of the Royal Festival Hall, London, England," Acustica 85, 547-559 (1999).

${ }^{7}$ T. Hidaka and L. L. Beranek, "Objective and subjective evaluations of twenty-three opera houses in Europe, Japan, and the Americas," J. Acoust. Soc. Am. 107, 368-383 (2000).

${ }^{8}$ T. Hidaka and N. Nishihara, "Objective evaluation of chamber-music halls in Europe and Japan," J. Acoust. Soc. Am. 116, 357-372 (2004).

${ }^{9}$ Y. J. Choi and F. R. Fricke, "Evaluation of the relative acoustic performance of two auditoria using measurements and auralization," Acta. Acust. Acust. 91, 1051-1062 (2005).

${ }^{10}$ Foreningen Spillesteder.dk, "Spillesteds-undersøgelse, 2005 [Survey of music venues, 2005]," available online at: http://www.spillesteder.dk/ temperatur_2005.htm (Last viewed August, 8, 2008; in Danish).

${ }^{11}$ P. White, "Where to use processors and why: Part 3," Sound on Sound 13, 242-246 (1997).

${ }^{12}$ The critical distance is the distance from a sound source at which the reverberant sound energy is equal to the energy of the sound radiating directly from the sound source. At greater distances from the source, the reverberant field dominates the sound received. The critical distance decreases with increasing reverberation time.

${ }^{13}$ A. C. Gade, "Investigations of musicians room acoustic conditions in concert halls. I. Methods and laboratory experiments," Acustica 69, 193-203 (1989).

${ }^{14} \mathrm{~A}$. C. Gade, "Investigations of musicians room acoustic conditions in concert halls. II. Field experiments and synthesis of results," Acustica 69, 249-262 (1989).

${ }^{15}$ R. C. Cabot, C. R. Genter, and T. Lucke, "Sound levels and spectra of rock-music," J. Audio Eng. Soc. 27, 267-284 (1979).

${ }^{16}$ K. Dibble, "Hearing loss \& music," J. Audio Eng. Soc. 43, 251-266 (1995).

${ }^{17}$ M. Barron, "The subjective effects of first reflections in concert hallsThe need for lateral reflections," J. Sound Vib. 15, 475-494 (1971).

${ }^{18}$ A. C. Gade, "Subjective room acoustic experiments with musicians, Report 32, Acoustics Laboratory," Ph.D. thesis, Technical University of Denmark, Lyngby, Denmark (1982).

${ }^{19}$ H. Kuttruff, Room Acoustics, 4th ed. (Spon, London, 2000).

${ }^{20}$ ISO 3382, Acoustics-Measurements of the Reverberation Time of Rooms with Reference to Other Acoustical Parameters, 2nd ed. (International Organization for Standardization, Geneva, Switzerland, 1997).

${ }^{21}$ N. W. Larsen, E. Olmos, and A. C. Gade, "Acoustics in halls for rock music," in Joint Baltic-Nordic Acoustics Meeting (BNAM), Mariehamn, Finland, (2004).

${ }^{22}$ E. Meyer, D. Kunstmann, and H. Kuttruff, "Über einige Messungen zur Schallabsorption von Publikum (On some measurements of sound absorption of the audience)," Acustica 14, 119-124 (1964).

${ }^{23}$ U. Kath and W. Kuhl, "Messungen zur Schallabsorption von Personen auf ungepolsterten Stühlen (Measurements of sound absorption of people on unupholstered seats)," Acustica 14, 50-55 (1964).

${ }^{24}$ G. Adams, "The room environment," in Loudspeaker and Headphone Handbook, edited by J. Borwick, (Butterworths, London, 1988), pp. 264318. 